\title{
Induction of cyclooxygenase-2 in human endometrial stromal cells by malignant endometrial epithelial cells: evidence for the involvement of extracellularly regulated kinases and CCAAT/enhancer binding proteins
}

\author{
M Tamura ${ }^{1,2}$, S Sebastian ${ }^{1}$, S Yang ${ }^{1}$, B Gurates ${ }^{1}$, Z Fang ${ }^{1}$, K Okamura ${ }^{2}$ and \\ S E Bulun ${ }^{1}$ \\ ${ }^{1}$ Departments of Obstetrics and Gynecology and Molecular Genetics, The University of Illinois at Chicago, Chicago, Illinois 60612, USA \\ ${ }^{2}$ Department of Obstetrics and Gynecology, Tohoku University School of Medicine, Sendai 980-8574, Japan \\ (Requests for offprints should be addressed to S E Bulun; Email: sbulun@nmh.org) \\ (S E Bulun is now at Northwestern University, Feinberg School of Medicine, Department of Obstetrics and Gynecology, 333 E Superior Street, \\ Suite 484, Chicago, IL 60611, USA)
}

\begin{abstract}
We previously reported that human malignant endometrial epithelial cell conditioned medium (MECM) up-regulated cyclooxygenase (COX)-2 mRNA and protein levels in human normal endometrial stromal cells (ESC). Here we showed that pretreatment with a selective inhibitor of the extracellularly regulated kinase (ERK)1/2 signaling pathway blocked the MECM-induced COX-2 expression in ESC. Transient transfection assays indicated critical roles of a cAMP response element (CRE, $-59 /-53 \mathrm{bp}$ ) and a nuclear factor for interleukin (IL)-6 expression (NF-IL6) site (-132/-124 bp) in the regulation of basal and MECM-induced activity of COX-2 gene promoter in ESC. Employing electrophoretic mobility shift assays, we demonstrated that increased functional binding of CCAAT/enhancer binding protein (C/EBP) $\alpha$, C/EBP $\beta$ and upstream stimulatory factor-2 to the CRE and C/EBP $\alpha$ and C/EBP $\beta$ to the NF-IL6 site were, at least in part, responsible for MECM-induced COX-2 expression in ESC. Moreover, overexpression of $\mathrm{C} / \mathrm{EBP} \alpha$ and $\mathrm{C} / \mathrm{EBP} \beta$ significantly induced COX-2 promoter activity in ESC. Collectively, these results suggest that the basal and MECM-induced transcription of the COX-2 gene in ESC is regulated through a combination of the CRE and the NF-IL6 site by functional interactions of C/EBP $\alpha$ and C/EBP $\beta$.
\end{abstract}

Journal of Molecular Endocrinology (2003) 31, 95-104

\section{Introduction}

Cyclooxygenase (COX) is a key enzyme in prostaglandin (PG) synthesis. COX converts arachidonic acid that is released from membrane stores by phospholipase to $\mathrm{PGH}_{2}$, the common precursor for all PGs. Two different isoforms of COX, referred to as COX-1 and COX-2, have been identified. They share over $60 \%$ identity at the amino acid level and have similar enzymatic activities, but although they catalyze the same reaction, these two isoforms may have distinct biological functions (Tazawa et al. 1994, Williams \& DuBois 1996). COX-1 is constitutively expressed in most mammalian tissues and is thought to carry out housekeeping functions. In contrast, COX-2 mRNA and protein are normally undetectable in most tissues, but can be rapidly induced in response to various cytokines and growth factors (Inoue et al. 1995, Potter et al. 2000, Thomas et al. 2000).

Supported by a plethora of experimental evidence, COX-2 expression emerged as a highly promising therapeutic target not only in the treatment of many inflammatory diseases but also several types of human cancers. Enhanced expression of COX-2, but not COX-1, has been found in colon (Sano et al. 1995), pancreatic (Tucker et al. 1999) and gastric cancer tissues (Ristimäki et al. 1997). Previous studies have shown that overexpression of COX-2 reduces the rate of apoptosis 
(Souza et al. 2000), increases the invasiveness of malignant cells (Tsujii et al. 1997) and promotes angiogenesis (Tsujii et al. 1998). The proposal that COX-2 contributes to carcinogenesis is supported further by compelling evidence that inhibitors of COX activity protect against colon, mammary, esophageal and lung cancer in humans (Subbaramaiah et al. 1997, Souza et al. 2000). Thus, COX-2 expression is important in cancer development.

We previously reported (Tamura et al. 2002a) that human malignant endometrial epithelial cell conditioned medium (MEGM) increased COX-2 mRNA and protein levels in human normal endometrial stromal cells (ESG). These results are suggestive of a cross-talk between malignant epithelial cells and surrounding stromal cells to favor COX-2 expression in the endometrial tumors. Moreover, using transient transfection assays, we found that the $-360 /+56$ bp region of the COX-2 promoter gene was critical for induction of promoter activity by MECM and that this MECM-responsive region contained a nuclear factor (NF)- $\mathrm{kB}$ site at -222 to $-213 \mathrm{bp}$. Employing electrophoretic mobility shift assays, we further demonstrated that binding of $\mathrm{NF}-\mathrm{\kappa B}$ p65 to this $\mathrm{NF}-\kappa \mathrm{B}$ binding site was, at least in part, responsible for the COX-2 promoter activation by MECM.

However, the molecular signaling mechanisms by which MECM induces the COX-2 transcription in ESC are not completely understood. We hypothesized that the optimal effect of MECM required

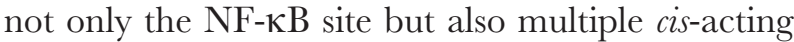
elements and/or cell signaling affected through a variety of cancer cell-secreted factors. Thus, we have attempted to identify the signal transduction pathway(s) involved and to characterize the critical cisacting elements that mediate induction of the COX-2 gene by MEGM in ESG.

\section{Materials and methods}

\section{Reagents and antibodies}

U0126 (a specific inhibitor of extracellularly regulated kinase (ERK) 1/2, also known as p42/p44 mitogen activated protein kinase (MAPK)), SB203580 (a specific inhibitor of p38 MAPK) and Spl consensus double-stranded oligonucleotide were purchased from Promega (Madison, WI, USA). Actinomycin D (Act D; general transcription inhibitor) was purchased from Sigma-Aldrich (St Louis, MO, USA). Antibodies against cAMP response element binding protein (CREB)-1, activating transcription factor (ATF)-1, ATF-2, CGAAT/enhancer binding protein (C/ $\mathrm{EBP}) \alpha, \mathrm{C} / \mathrm{EBP} \beta, \mathrm{C} / \mathrm{EBP} \delta$, upstream stimulatory factor (USF)-1 and USF-2 were purchased from Santa Cruz Biotechnology (Santa Cruz, CA, USA). All other materials used in the study are indicated in the appropriate context below.

\section{Cell culture}

Human normal endometrial stromal cells (ESG) were cultured using a protocol previously reported (Tamura et al. 2002b). Confluent ESG were serum-deprived for $16 \mathrm{~h}$ in serum-free Dulbecco's modified Eagle's medium-Ham's F12 (DMEM/ F12) before being subjected to the following two treatments: (i) serum-free medium as the baseline control and, (ii) serum-free medium conditioned with Ishikawa human malignant endometrial epithelial cells (malignant epithelial cell conditioned medium abbreviated as MECM). Treated ESC were then used to isolate total RNA for reverse transcriptase-polymerase chain reaction (RT-PCR), whole extracts for Western blot analysis and nuclear extracts for electrophoretic mobility shift assay (EMSA). The cells were studied at passage 4-6. The conditioned medium was generated in the following fashion. After Ishikawa cells were grown to confluence, culture medium was switched to serum-free DMEM/F12 for a 16-h-washout period to collect MEGM. Then, cells were incubated in new serum-free DMEM/F12 for $72 \mathrm{~h}$ to allow accumulation of secreted factors in the medium. We collected MECM and centrifuged it to remove the cell debris. The supernatant was transferred to a clean tube and immediately frozen and kept at $-80^{\circ} \mathrm{C}$ for future use.

\section{Semi-quantitative RT-PCR amplification}

Total RNA $(5 \mu \mathrm{g})$ was isolated from ESC using the RNeasy mini kit (Qiagen, Valencia, CA, USA), following the protocol suggested by the manufacturer. For RT-PCR analysis of COX-2 and glyceraldehyde-3-phosphate dehydrogenase (GAPDH) mRNA, the SuperScript First-Strand Synthesis System (Invitrogen, Carlsbad, CA, USA) was used to synthesize the first strand cDNA 
as instructed by the supplier. The nucleotide sequences of the primer pairs employed and the PCR conditions have been reported previously (Tamura et al. 2002b). ESG were exposed to MEGM with or without signal transduction inhibitor for $8 \mathrm{~h}$. Aliquots of the reaction products were analyzed by electrophoresis in an agarose gel and ethidium bromide staining. PGR products were quantified using the Quantity One 1-D Analysis Software (Bio-Rad Laboratories, Hercules, CA, USA) as a densitometer. We assert that these data are semi-quantitative (relative to control GAPDH) based on the following test performed prior to data analysis, as previously shown (Tamura et al. 2002a). Briefly, both products were assayed in the linear response range of the RT-PCR amplification process. The cycle number used in this assay was determined by finding the midpoint of linear amplification on a sigmoid curve for both amplification products with cycle numbers 25-42 plotted against band density.

\section{Western blotting}

Western blotting was performed as previously described (Tamura et al. 2002a), using $20 \mu \mathrm{g}$ of whole cell protein extract in each sample that was exposed to MECM with or without signal transduction inhibitor for $8 \mathrm{~h}$ and anti-COX-2 polyclonal antibody (Santa Cruz Biotechnology). Band intensity of protein expression was quantitated using the Molecular Analyst version 1.5 software (Bio-Rad Laboratories).

\section{Plasmid construction, transient transfections and luciferase assays}

Construction of the deletion mutant containing specific regions of the human COX-2 gene promoter in the luciferase reporter vector pGL3 Basic (Promega) was accomplished using PCR amplification of the desired region using the recombinant plasmid containing a 7-kb promoter region of the human COX-2 gene (a generous gift from Dr Stephen M Prescott) as the template. Mutant constructs were constructed as described previously (Tamura et al. 2002b). Briefly, for the cAMP response element (CRE), TTCGTCA was changed to TtgagCt and, for the nuclear factor for interleukin (IL)-6 expression (NF-IL6) site, the sequence was changed from TTACGCAAT to TTggtaccT; the lower case nucleotides indicate the mutations.

Transfections into ESG incubated with control media or MECM were performed using the LipofectAMINE PLUS reagent (Invitrogen), following the protocol provided by the manufacturer. Each transfection was carried out using $0 \cdot 4 \mu \mathrm{g}$ firefly luciferase reporter plasmid construct that contains deletion or site-specific mutants of the human COX-2 gene promotor and $1 \mathrm{ng}$ of an internal control reporter plasmid pRL-TK (Renilla luciferase-thymidine kinase) supplied by Promega. Cotransfection was performed by adding $0 \cdot 1 \mu \mathrm{g}$ pcDNA3 1 expression plasmid (Invitrogen), which contains the cDNA of either $\mathrm{C} / \mathrm{EBP} \alpha$ (human) or $\mathrm{C} / \mathrm{EBP} \beta$ (mouse) (generous gifts from Drs Gretchen Darlington and Gokhan Hotamisligil). Firefly and Renilla luciferase activities were sequentially measured using the Dual-Luciferase Reporter Assay System (Promega) and LUMAT LB9507 luminometer (Berthold Technologies GmbH \& Co.KG, Bad Wildbad, Germany).

\section{Electrophoretic mobility shift assay (EMSA)}

Nuclear protein was extracted from whole cells using NE-PER Nuclear and Cytoplasmic Extraction Reagents (Pierce, Rockford, IL, USA), following the protocol suggested by the manufacturer. EMSA was performed as previously described (Tamura et al. 2002a), using $0.5 \mu \mathrm{g}$ nuclear protein extract in each sample. We used the following double-stranded probes. The CRE probe (5'-AAACAGTCATT TCGTCACATGGGCTTG-3') was designed to represent a 27-bp-long sequence $(-69 /-43 \mathrm{bp})$ in the promoter region of COX-2 gene. The NF-IL6 site probe (5'-CACGGGGGTTAGGGAATTTT TTTAA-3') was designed to represent a 25-bplong sequence $(-140 /-116 \mathrm{bp})$. The underlined nucleotides indicate the transcription factor binding domain and they are $100 \%$ identical with the consensus sequences.

\section{Statistical analysis}

Statistical analysis for comparison between treatment groups was performed by one-way analysis of variance followed by Tukey's multiple comparison test. A $P$ value $<0.05$ was considered significant. All values are given as the mean, with the bars (in the Figures) showing standard errors of the mean. 


\section{Results}

\section{MECM-mediated COX-2 induction is blocked by an inhibitor of ERK1/2 signal transduction pathway}

We initially carried out experiments to evaluate the optimal conditions for determining the effects of MECM on COX-2 mRNA levels in ESC. To determine where PCR amplification for COX-2 mRNA was in the logarithmic phase, total RNA isolated from ESG treated with MECM was reverse transcribed and was amplified under different cycle numbers. Single PCR products were obtained for COX-2. A linear relationship between PGR products and amplification cycles was observed for COX-2 treated with MEGM in ESG (Tamura et al. 2002a). Consequently, 38 cycles for COX-2 were employed for quantification. The time course of COX-2 mRNA abundance as examined by RTPCR showed an increase following treatment at $4 \mathrm{~h}$, and peaked at $8 \mathrm{~h}$ (Fig. 1A). PCR was also performed using an aliquot of the RT products for the housekeeping gene GAPDH mRNA to control the RT reaction, PCR efficiency and equal starting amounts of total RNA. There was no apparent change in the GAPDH mRNA abundance upon MECM treatment. COX-2 protein levels were also induced after MECM treatment at $8 \mathrm{~h}$ and remained detectable up to $24 \mathrm{~h}$ (Fig. 1B). Equal loading of protein in each lane was confirmed by Coomassie blue staining of samples fractionated on SDS-PAGE. Quantitative densitometry for three independent experiments confirmed these results. Based on these observations, the ESC were pretreated with various inhibitors of signal transduction for $30 \mathrm{~min}$ and then incubated with MEGM for $8 \mathrm{~h}$. One micromole ERK1/2 specific inhibitor, $\mathrm{U} 0126\left(\mathrm{IC}_{50} 0.53 \mu \mathrm{M}\right.$, Favata et al. 1998) caused significant decreases in the density of the COX-2 mRNA band (Fig. 1G). COX-2 immunoblot experiments confirmed that this inhibitor indeed abolished the increased COX-2 protein otherwise seen upon MEGM treatment (Fig. 1D). Equal loading of protein in each lane was confirmed by intensity of bands in a portion of the Coomassie blue-stained gel. In contrast, pretreatment with several concentrations $(0 \cdot 1 \mu \mathrm{M}, 1 \mu \mathrm{M}$ and $2 \mu \mathrm{M})$ of the p38 MAPK inhibitor, SB203580 $\left(\mathrm{IC}_{50} 0.6 \mu \mathrm{M}\right.$, Cuenda et al. 1995) did not block MECM stimulation of COX-2 mRNA in ESG (Fig. 1G). As a positive control, SB203580 inhibited IL-1 $\beta$ stimulated COX-2 mRNA expression in HeLa cells (data not shown), as previous investigators reported (Ridley et al. 1998). Pretreatment with $10 \mu \mathrm{g} / \mathrm{ml}$ Act D (a general transcriptional inhibitor) also abolished the MECM-mediated induction of COX-2 gene, demonstrating the requirement of new RNA synthesis. To check the effects of these inhibitors (U0126 and SB203580) on unstimulated ESC, ESC were also pretreated with them and then incubated with control DMEM/F12. No apparent changes in the basal levels of COX-2 mRNA in ESG were observed (data not shown). Additionally, we have previously demonstrated that Act $\mathrm{D}$ also had no effect on basal levels of the COX-2 mRNA expression in ESC (Tamura et al. 2002a). These results suggested that MECM-induced COX-2 expression in ESC is mediated via activation of ERK1/2 and not via the p38 MAPK pathway.

\section{Activation of the COX-2 promoter by MECM requires CRE and the NF-IL6 site}

We have previously reported that the $-360 /+56$ region was shown to be important for MECMmediated induction, since only the $-360 /+56$ bp construct $(\operatorname{phCOX} 2(-360 /+56))$ demonstrated a statistically significant induction upon treatment with MECM (Tamura et al. 2002a). Sequence analysis of this region and a literature review (Tazawa et al. 1994) revealed the existence not only of an NF- $\mathrm{KB}$ site $(-222 /-213 \mathrm{bp})$ but also a CRE ( - 59/ - 53 bp) and an NF-IL6 site ( -132 / $-124 \mathrm{bp}$ ) (Fig. 2A). Therefore, using the $-218 /$ +56 bp reporter construct (phCOX2 $(-218 /+56))$, we attempted to identify and characterize the critical cis-acting elements that mediate induction of the COX-2 gene in ESG. Site-directed mutations of the CRE and the NF-IL6 site either alone or in combination significantly reduced both baseline and MECM-induced COX-2 promoter activity in ESC (Fig. 2B). Compared with the disruption of the NF- $\kappa \mathrm{B}$ site, the disruption of each site gave rise to a greater decrease in baseline and MEGM-dependent promoter activity (Tamura et al. 2002a). Thus, the presence of CRE and the NF-IL6 site were required for maximum MECM-mediated induction of COX-2 promoter in ESC.

\section{Identification of the proteins which bind to cis-acting elements in CRE and the NF-IL6 site}

EMSA was performed using nuclear proteins from ESC treated with or without MECM to determine 
(a)
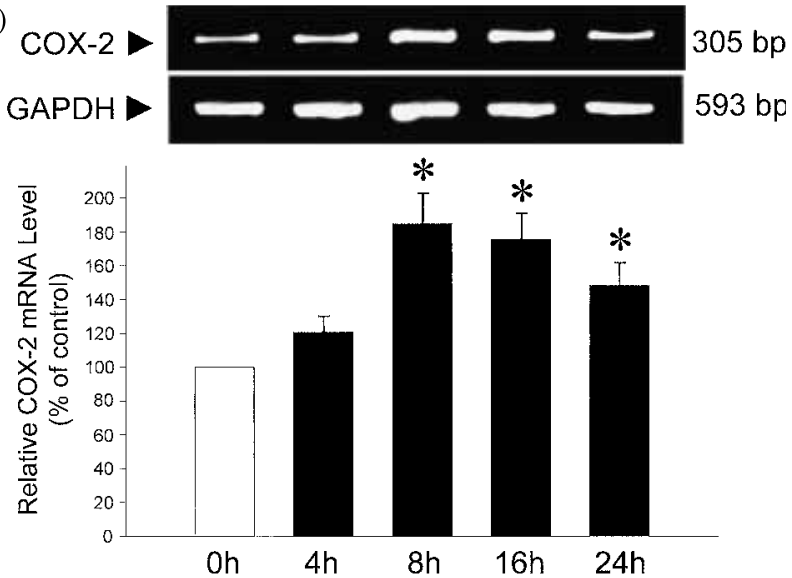

(c)
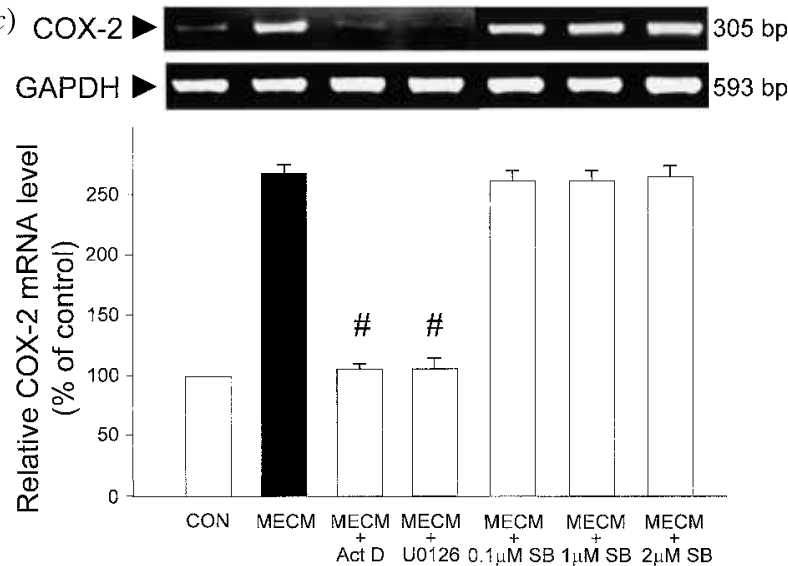

(b)

Coomassie bluestained gel
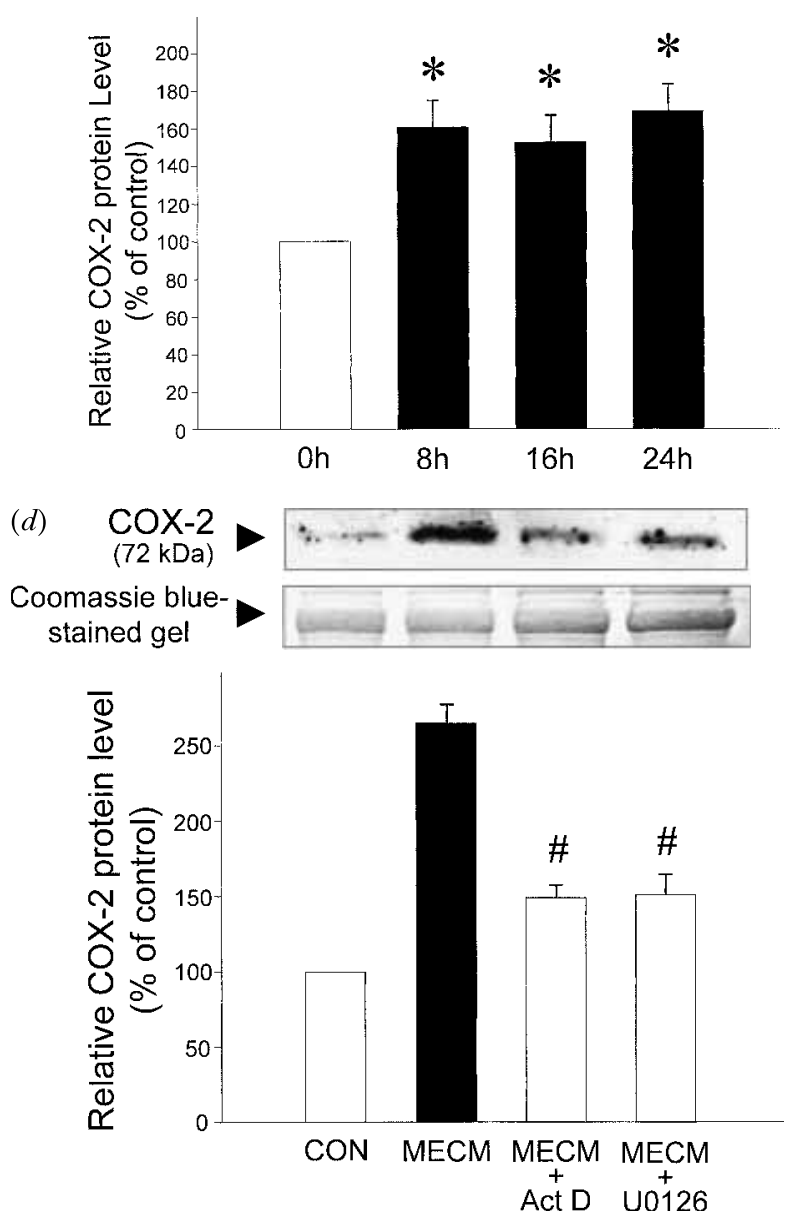

Figure 1 Effects of malignant endometrial epithelial cell conditioned medium (MECM) on COX-2 mRNA and protein levels in human endometrial stromal cells (ESC). (a, b) ESC treated with MECM for $0 \mathrm{~h}$ (control) to $24 \mathrm{~h}$. (c, d) ESC were exposed to control medium (CON), MECM, MECM+10 $\mu \mathrm{g} / \mathrm{ml}$ actinomycin D (Act D), MECM+1 $\mathrm{MM} \mathrm{U0126}$ (a specific inhibitor of extracellularly regulated kinase (ERK) 1/2) or MECM+0.1 $\mu \mathrm{M}, 1 \mu \mathrm{M}$ or $2 \mu \mathrm{M}$ SB203580 (SB) (a specific inhibitor of p38 mitogen activated protein (MAP) kinase) for $8 \mathrm{~h}$. Inhibitors were added 30 min before MECM stimulation. $(\mathrm{a}, \mathrm{c})$ The semi-quantitative RT-PCR shown at the top is representative of three independent experiments. Band sizes were: COX-2, $305 \mathrm{bp}$; GAPDH, $593 \mathrm{bp}$. Summary data for quantitative densitometry for the three experiments are given at the bottom. Relative levels of COX-2 mRNA expression were determined by densitometric scanning of the bands and normalized to the GAPDH signal. (b, d) The Western blot analysis shown at the top is representative of three independent experiments. COX-2 protein was detected at $72 \mathrm{kDa}$. Equal loading of protein in each lane was confirmed by intensity of bands in a portion of the Coomassie blue-stained gel. Summary data for quantitative densitometry for the three experiments are given at the bottom. Mean \pm S.E.M. values are depicted for mRNA or protein abundance expressed as a percentage in control ESC. ${ }^{\star} P<0.05$ compared with control ESC; ${ }^{\#} P<0.05$ compared with MECM-treated ESC.

the protein/DNA binding activities at the CRE and the NF-IL6 site. In the case of CRE, the shifted complex from ESC incubated with control medium was composed of two specific complexes, 1 and 2.
However, nuclear extract prepared from MECMtreated cells showed more intense signals for both complex 1 and 2, indicating increased protein/ DNA binding activity at CRE upon MECM 
(a) Human COX-2 gene 5'-flanking region

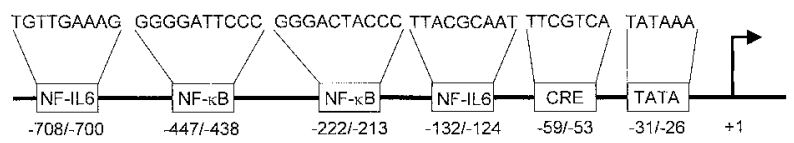

(b) Human cox-2 gene $5^{-}$-flanking region

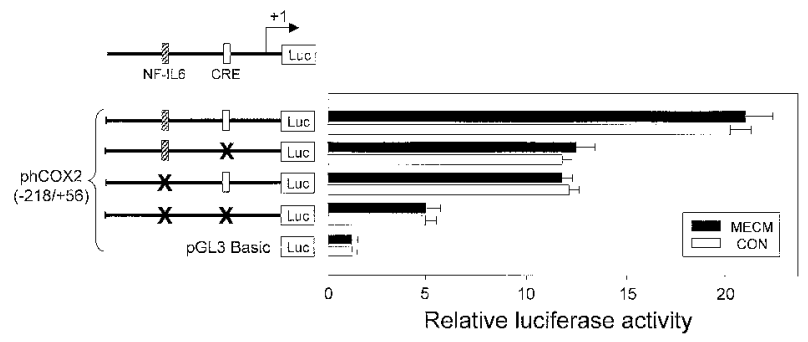

Figure 2 Analysis of the region responsible for the promoter activity of the human COX-2 gene. (a) Locations of potential response elements in the 5'-flanking region of the human COX-2 gene. Nucleotides are numbered negatively with nucleotide +1 corresponding to the transcriptional start site. (b) Selected mutations of two cis-acting elements (cAMP response element (CRE) and the nuclear factor (NF)-IL6 site) alone or in combination significantly decreased MECM-induced promoter activity indicating the critical roles of each one of the DNA binding sites. phCOX2 $(-218 /+56),-218 /+56$ bp reporter construct; CON, control medium; MECM, malignant endometrial epithelial cell conditioned medium; Luc, luciferase reporter gene. Site-specific mutation is indicated by an X. Results are expressed as the mean \pm S.E.M. of three independent experiments performed in triplicate.

treatment (Fig. 3A). Preincubation with cold CRE or NF-IL6 probes completely abolished both shifted bands. On the other hand, a consensus Spl-binding sequence had no effect on the band intensity, confirming the specificity of the reaction.

A similar increase in the protein/DNA binding activity at the NF-IL6 site by MECM-treated ESC nuclear proteins was also observed (Fig. 3A). The difference was that instead of two shifted bands as in the case of CRE, only one shifted band was formed with the NF-IL6 site probe. Again, preincubation with cold CRE or NF-IL6 site probes abolished this band, whereas Spl-specific sequence had no effect. Both DNA-protein complexes could be competed away successfully using either probe.

Since previous studies (Inoue et al. 1995, Potter et al. 2000, Thomas et al. 2000) have demonstrated functional binding of CREB, C/EBPs and USF to either CRE or NF-IL6 sites, antibody competition of specific proteins from the nuclear extracts prior to the EMSA analysis was attempted. Using the CRE probe and nuclear extract from MECMtreated ESC, antibody competition of either $\mathrm{C} / \mathrm{EBP} \alpha$ or $\mathrm{C} / \mathrm{EBP} \beta$ abolished the formation of complex 1 and reduced the band intensity of complex 2 (Fig. 3B). In contrast, antibody competition of USF-2 resulted in reduced signal intensity for complex 2, but had no effect on complex 1 formed by the CRE probe. On the other hand, antibodies against CREB-1, ATF-1, ATF-2, $\mathrm{C} / \mathrm{EBP} \delta$ or USF-1 did not alter the intensity or rate of migration of either complex formed by the
CRE probe. It should be noted that a modest signal remained for complex 2 following antibody competition with $\mathrm{C} / \mathrm{EBP} \alpha, \mathrm{C} / \mathrm{EBP} \beta$ or USF-2 (Fig. $3 \mathrm{~B}$ ) and after preincubation with the combination of all the three antibodies (data not shown); therefore, this complex formed by the CRE probe may contain additional protein(s). Next, to determine the identity of the protein which binds to the NF-IL6 site, MECM-treated ESC nuclear extract was selectively competed for GREB-1, ATF-1, ATF-2, C/EBP $\alpha$, G/EBP $\beta$, $\mathrm{C} / \mathrm{EBP} \delta$, USF-1 or USF-2. As shown in Fig. 3C, antibody competition of $\mathrm{C} / \mathrm{EBP} \alpha$ or C/EBP $\beta$ completely abolished the band shift indicating that this complex contained both of these proteins.

\section{Overexpression of C/EBP $\alpha$ and C/EBP $\beta$ induces COX-2 activity in ESC}

To directly examine the role of $\mathrm{C} / \mathrm{EBP} \alpha$ and $\mathrm{C} / \mathrm{EBP} \beta$ in regulating the $\mathrm{COX}-2$ promoter activity in ESC, cotransfection experiments were performed using the $-218 /+56 \mathrm{bp}$ reporter construct (phCOX2 $(-218 /+56))$ and $\mathrm{C} / \mathrm{EBP} \alpha$ or $\mathrm{C} / \mathrm{EBP} \beta$ expression plasmids. As shown in Fig. 4, irrespective of the treatment conditions (control or MECM), overexpression of $\mathrm{C} / \mathrm{EBP} \alpha$ or $\mathrm{C} / \mathrm{EBP} \beta$ resulted in the transactivation of $\mathrm{COX}-2$ gene promoter by $2 \cdot 5$ - or $3 \cdot 0$-fold respectively in ESC. These results further confirmed that COX-2 gene induction in ESC by MECM is, at least in part, mediated by $\mathrm{C} / \mathrm{EBP} \alpha$ and $\mathrm{C} / \mathrm{EBP} \beta$. 


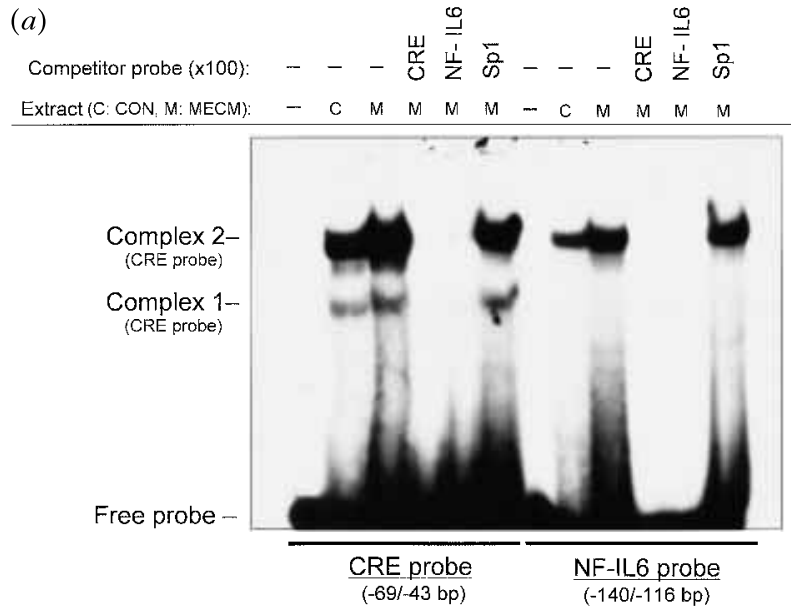

(b)

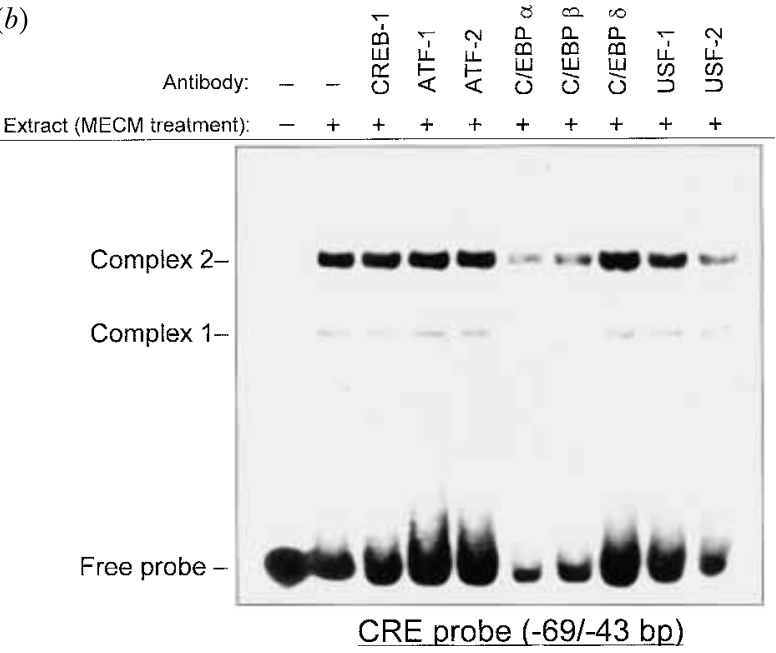

$(c)$

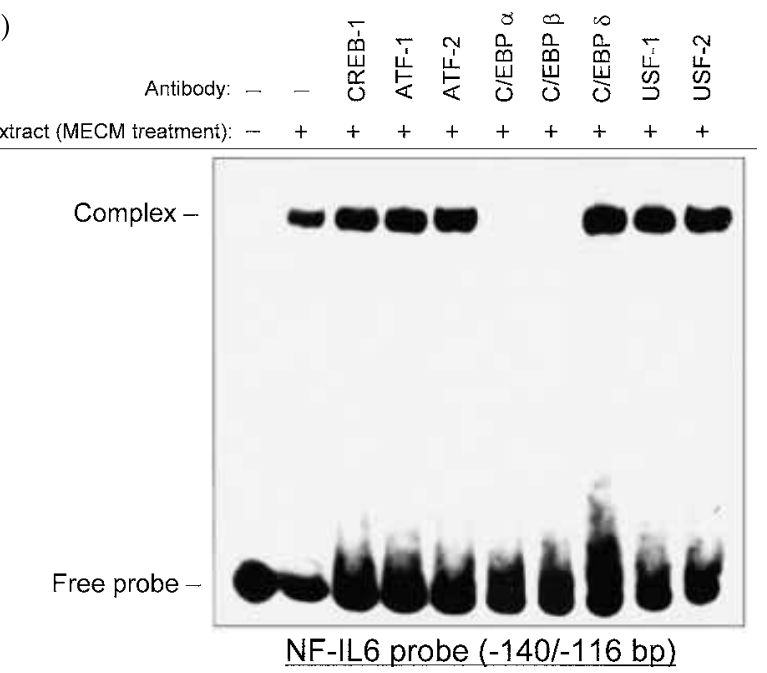

Figure 3 EMSA to identify the proteins that bind cAMP response element (CRE) and nuclear factor (NF)-IL6. (a) Competitive EMSAs were performed with a CRE and a NF-IL6 radiolabeled probe and nuclear extract from control medium (CON)- or malignant endometrial epithelial cell conditioned medium (MECM)-treated normal human endometrial stromal cells (ESC). A probe containing an Sp1 binding site was used as a negative control. A 100-fold molar excess of unlabeled CRE, NF-IL6 or Sp1 oligonucleotides was used in the competition reactions. (b, c) Immunodepletion studies were performed with a CRE (b) or a NF-IL6 (c) radiolabeled probe and nuclear extract from MECM-treated ESC and antibodies against transcription factors that may potentially bind to both the CRE and the NF-IL6 site. Results were reproduced in two other experiments.

\section{Discussion}

In the present study, we have demonstrated involvement of the ERK1/2 signaling pathway in the induction of the COX-2 gene by MEGM in human normal ESC. U0126 is an organic compound (1,4-diamino-2,3-dicyano-1,4bis(2-aminophenylthio)butadiene) that has been identified as an inhibitor of AP-1 transactivation in cell-based reporter assays (Favata et al. 1998). It specifically inhibits the phosphorylation and activation of ERK1/2. U0126 does not affect the phosphorylation of mitogen-activated protein kinase kinase (MEK), the upstream kinase of ERK, at concentrations sufficient to inhibit ERK phosphorylation. It thus appears that U0126 inhibits MEK directly by inhibiting the catalytic activity of the active enzyme. Recent studies have suggested that Ras (the upstream kinase of MEK) activation may induce COX-2 expression in several 


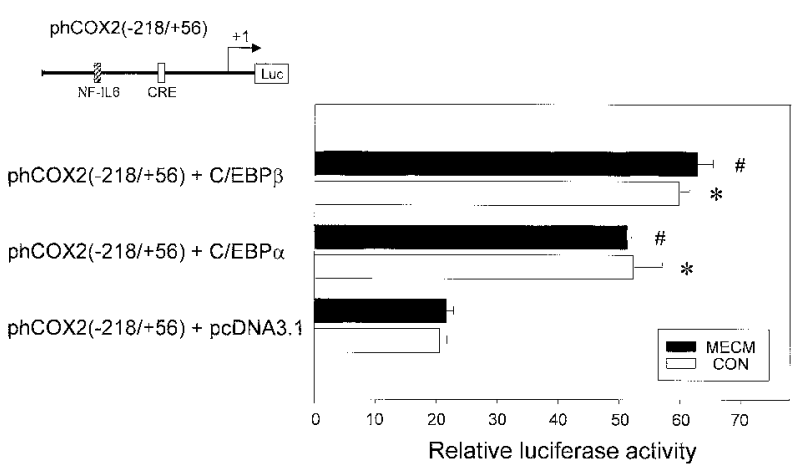

Figure 4 Effects of CCAAT/enhancer binding protein (C/EBP) isoforms on responsiveness of the COX-2 promoter to control medium (CON) or malignant endometrial epithelial cell conditioned medium (MECM) in human endometrial stromal cells (ESC). The $-218 /+56$ bp reporter construct (phCOX2 $(-218 /+56)$ ) was cotransfected with the $\mathrm{C} / \mathrm{EBP} \alpha$ expression vector, the C/EBP $\beta$ expression vector or the same amount of empty expression vector pcDNA3.1. Results are expressed as the mean \pm S.E.M. of three independent experiments performed in triplicate. ${ }^{*} P<0.05$ compared with phCOX-2(-218/+56) plus pcDNA3.1 treated with control medium. ${ }^{\#} P<0.05$ compared with phCOX-2(-218/+56) plus pcDNA3.1 treated with MECM.

systems (Subbaramaiah et al. 1996, Sheng et al. 1998). Activated, oncogenic Ras was inducibly expressed in Rat-1 fibroblasts with a concomitant increase in COX-2 expression (Sheng et al. 1998). In this cell line, a specific ERK inhibitor was found to suppress COX-2 induction by Ras, suggesting that ERK1/2 activation is required for Rasdependent induction of COX-2. Similarly, elevated levels of COX-2 were detected in Ras-transformed mammary epithelial cells (Subbaramaiah et al. 1996). Therefore, it is possible that MEGM can activate $\mathrm{R}$ as and that the ERK1/2 signaling pathway is important in the regulation of COX-2 by MECM. The suppression of MECM-induced COX-2 expression by U0126 (ERK1/2 inhibitor) clearly supports this observation.

Using transient transfection assays, we identified that the CRE at - 59/-53 and the NF-IL6 site at $-132 /-124$ in the COX-2 promoter gene were critical for the optimal COX-2 transcriptional increase in ESC. However, since the reporter construct containing the COX-2 promoter region $-218 /+56$ exhibited the maximum stimulation and we did not employ additional experiments to corroborate this observation, we do not rule out the possibility of the cooperative involvement of the other sites to elicit COX-2 promoter in ESC. Using EMSA, we demonstrated that increased functional binding of $\mathrm{C} / \mathrm{EBP} \alpha, \mathrm{C} / \mathrm{EBP} \beta$ and $\mathrm{USF}-2$ to the $\mathrm{CRE}$ and $\mathrm{C} / \mathrm{EBP} \alpha$ and $\mathrm{C} / \mathrm{EBP} \beta$ to the NF-IL6 site were, at least in part, responsible for MECM-induced COX-2 expression in ESC. Several trans-activating factors with a leucine zipper motif that specifically interact with the CRE have been identified (Lalli \& Sassone-Corsi 1994). Inoue et al. (1995) reported that $\mathrm{C} / \mathrm{EBP} \delta$ bound to both the CRE and the NF-IL6 site and increased the COX-2 gene promoter activity mainly through the CRE. Timchenko et al. (1995) showed a functional interaction between USF and $\mathrm{C} / \mathrm{EBP} \alpha$ in the autoregulation of $\mathrm{C} / \mathrm{EBP} \alpha$ gene, where overexpression of $\mathrm{C} / \mathrm{EBP} \alpha$ resulted in the enhanced binding of USF. Taken together with overexpression of $\mathrm{C} / \mathrm{EBP} \alpha$ or $\mathrm{G} / \mathrm{EBP} \beta$ studies, these data are suggestive of critical roles for $\mathrm{C} / \mathrm{EBP} \alpha$ and $\mathrm{G} / \mathrm{EBP} \beta$ in mediating MEGM-induced COX-2 gene expression in ESG.

The ERK1/2 might phosphorylate C/EBPs and enhance its ability to activate COX-2 transcription. Consistent with this notion are studies in other systems demonstrating that MAPK can enhance the transactivation properties of $\mathrm{C} / \mathrm{EBP} \beta$ via the phosphorylation of threonine-235 (Nakajima et al. 1993, Kowenz-Leutz et al. 1994). In addition, ERK $1 / 2$ activation can regulate the expression of numerous genes by activating NF-אB (Zhao \& Lee 1999). Recently, several investigators have described physical and functional interactions between $\mathrm{C} / \mathrm{EBP}$ and NF- $\mathrm{BB}$ family members (Kinoshita et al. 1992, LeClair et al. 1992). These transcription factors directly associate via the b-Zip domain of $\mathrm{C} / \mathrm{EBP}$ and the Rel homology domain of p65 or p50. Supporting this model are experiments by Stein et al. (1993), which showed that the presence of $\mathrm{NF}-\kappa \mathrm{B}$ p65 significantly enhanced the binding of $\mathrm{C} / \mathrm{EBP}$ family proteins to their DNA-binding sites. In this case, the addition of p65 did not alter the mobility of the C/EBP-DNA complex from the control. The authors suggested that the p65 interaction may have altered the conformation of $\mathrm{C} / \mathrm{EBP}$, making it more stable. Interestingly, our studies suggest similarly that $\mathrm{G} / \mathrm{EBPs}$, which are induced by MECM, may play an important role in both the basal and induced transcriptional activity of COX-2 promoter and in the regulation of COX-2 
gene expression by enhancing the binding of $\mathrm{NF}-\kappa \mathrm{B}$ p65 to this promoter.

We conclude that, in endometrial stromal cells, MEGM-mediated induction of COX-2 expression is a complex process that requires input from multiple signaling pathways. Each pathway acts synergistically, the sum of their actions culminating in a dramatic increase in COX-2 transcription. Given the recent emphasis on COX-2 in cancer biology, this paracrine interaction may be important in the pathogenesis of endometrial cancer.

\section{Acknowledgements}

We are grateful to Drs Stephen M Prescott, Gretchen Darlington and Gokhan Hotamisligil for providing the plasmids.

This work was supported by NIH grant HD38691 to S E B and by a fellowship award to M T from the Japan Menopause Society, Tokyo, Japan.

\section{References}

Cuenda A, Rouse J, Doza YN, Meier R, Cohen P, Gallagher TF, Young PR \& Lee JC 1995 SB203580 is a specific inhibitor of a MAP kinase homologue which is stimulated by cellular stresses and interleukin-1. FEBS Letters 364 229-233.

Favata MF, Horiuchi KY, Manos EJ, Daulerio AJ, Stradley DA, Feeser WS, Van Dyk DE, Pitts WJ, Earl RA, Hobbs F, Copeland RA, Magolda RL, Scherle PA \& Trzaskos JM 1998 Identification of a novel inhibitor of mitogen-activated protein kinase kinase. Journal of Biological Chemistry 273 18623-18632.

Inoue H, Yokoyama C, Hara S, Tone Y \& Tanabe T 1995 Transcriptional regulation of human prostaglandin-endoperoxide synthase-2 gene by lipopolysaccharide and phorbol ester in vascular endothelial cells. Involvement of both nuclear factor for interleukin-6 expression site and cAMP response element. fournal of Biological Chemistry 270 24965-24971.

Kinoshita S, Akira S \& Kishimoto T 1992 A member of the C/EBP family, NF-IL6 $\beta$, forms a heterodimer and transcriptionally synergizes with NF-IL6. PNAS 89 1473-1476.

Kowenz-Leutz E, Twamley G, Ansieau S \& Leutz A 1994 Novel mechanism of C/EBP beta (NF-M) transcriptional control: activation through derepression. Genes and Development 8 2781-2791.

Lalli E \& Sassone-Corsi P 1994 Signal transduction and gene regulation: the nuclear response to cAMP. Fournal of Biological Chemistry 269 17359-17362.

LeClair KP, Blanar MA \& Sharp PA 1992 The p50 subunit of NF- $\mathrm{BB}$ associates with the NF-IL6 transcription factor. PNAS $\mathbf{8 9}$ 8145-8149.

Nakajima T, Kinoshita S, Sasagawa T, Sasaki K, Naruto M, Kishimoto T \& Akira S 1993 Phosphorylation at threonine-235 by a ras-dependent mitogen-activated protein kinase cascade is essential for transcription factor NF-IL6. PNAS 90 2207-2211.

Potter S, Mitchell MD, Hansen WR \& Marvin KW 2000 NF-IL6 and CRE elements principally account for both basal and interleukin- 1 beta-induced transcriptional activity of the proximal
528 bp of the PGHS-2 promoter in amnion-derived AV3 cells: evidence for involvement of C/EBP beta. Molecular Human Reproduction 6 771-778.

Ridley SH, Dean JL, Sarsfield SJ, Brook M, Clark AR \& Saklatvala J 1998 A p38 MAP kinase inhibitor regulates stability of interleukin-1-induced cyclooxygenase-2 mRNA. FEBS Letter 439 75-80.

Ristimäki A, Honkanen N, Jankala H, Sipponen P \& Harkonen M 1997 Expression of cyclooxygenase-2 in human gastric carcinoma. Cancer Research 57 1276-1280.

Sano H, Kawahito Y, Wilder RL, Hashiramoto A, Mukai S, Asai K, Kimura S, Kato H, Kondo M \& Hla T 1995 Expression of cyclooxygenase- 1 and -2 in human colorectal cancer. Cancer Research 55 3785-3789.

Sheng H, Williams CS, Shao J, Liang P, DuBois RN \& Beauchamp RD 1998 Induction of cyclooxygenase-2 by activated Ha-ras oncogene in Rat-1 fibroblasts and the role of mitogen-activated protein kinase pathway. Fournal of Biological Chemistry $\mathbf{2 7 3}$ 22120-22127.

Souza RF, Shewmake K, Beer DG, Cryer B \& Spechler SJ 2000 Selective inhibition of cyclooxygenase-2 suppresses growth and induces apoptosis in human esophageal adenocarcinoma cells. Cancer Research 60 5767-5772.

Stein B, Cogswell PC \& Baldwin AS Jr 1993 Functional and physical associations between NF- $\kappa$ B and C/EBP family members: a rel domain-bZIP interaction. Molecular and Cellular Biology 13 3964-3974.

Subbaramaiah K, Telang N, Ramonetti JT, Araki R, DeVito B, Weksler BB \& Dannenberg AJ 1996 Transcription of cyclooxygenase-2 is enhanced in transformed mammary epithelial cells. Cancer Research 56 4424-4429.

Subbaramaiah K, Zakim D, Weksler BB \& Dannenberg AJ 1997 Inhibition of cyclooxygenase: a novel approach to cancer prevention. Proceedings of the Society for Experimental Biology and Medicine 216 201-210.

Tamura M, Sebastian S, Yang S, Gurates B, Ferrer K, Sasano H, Okamura K \& Bulun SE $2002 a$ Up-regulation of cyclooxygenase-2 expression and prostaglandin synthesis in endometrial stromal cells by malignant endometrial epithelial cells: a paracrine effect mediated by prostaglandin $\mathrm{E}_{2}$ and nuclear factor-kB. Fournal of Biological Chemistry 277 26208-26216.

Tamura M, Sebastian S, Yang S, Gurates B, Fang Z \& Bulun SE $2002 b$ Interleukin- $1 \beta$ elevates cyclooxygenase- 2 protein level and enzyme activity via increasing its mRNA stability in human endometrial stromal cells: an effect mediated by extracellularly regulated kinase 1 and 2. Fournal of Clinical Endocrinology and Metabolism 87 3263-3273.

Tazawa R, Xu XM, Wu KK \& Wang LH 1994 Characterization of the genomic structure, chromosomal location and promoter of human prostaglandin $\mathrm{H}$ synthase-2 gene. Biochemical and Biophysical Research Communications 203 190-199.

Thomas B, Berenbaum F, Humbert L, Bian H, Bereziat G, Crofford L \& Olivier JL 2000 Critical role of C/EBPdelta and C/EBPbeta factors in the stimulation of the cyclooxygenase- 2 gene transcription by interleukin-1 beta in articular chondrocytes. European Fournal of Biochemistry 267 6798-6809.

Timchenko N, Wilson DR, Taylor LR, Abdelsayed S, Wilde M, Sawadogo M \& Darlington GJ 1995 Autoregulation of the human C/EBP alpha gene by stimulation of upstream stimulatory factor binding. Molecular and Cellular Biology 15 1192-1202.

Tsujii M, Kawano S \& DuBois RN 1997 Cyclooxygenase-2 expression in human colon cancer cells increases metastatic potential. PNAS 94 3336-3340.

Tsujii M, Kawano S, Tsuji S, Sawaoka H, Hori M \& DuBois RN 1998 Cyclooxygenase regulates angiogenesis induced by colon cancer cells. Cell 93 705-716. 
Tucker ON, Dannenberg AJ, Yang EK, Zhang F, Teng L, Daly JM, Soslow RA, Masferrer JL, Woerner BM, Koki AT \& Fahey TJ 3rd 1999 Cyclooxygenase-2 expression is up-regulated in human pancreatic cancer. Cancer Research 59 987-990.

Williams CS \& DuBois RN 1996 Prostaglandin endoperoxide synthase: why two isoforms? American Fournal of Physiology $\mathbf{2 7 0}$ G393-G400.
Zhao Q \& Lee FS 1999 Mitogen-activated protein kinase/ERK kinase kinases 2 and 3 activate nuclear factor- $\kappa$ B through IкB kinase- $\alpha$ and IкB kinase- $\beta$. Fournal of Biological Chemistry 274 8355-8358.

Received in final form 6 April 2003 Accepted 9 April 2003 